\title{
Pretreatments of cellulose pyrolysate for ethanol production by Saccharomyces cerevisiae, Pichia sp. YZ-1 and Zymomonas mobilis
}

\author{
Zhisheng Yu, Hongxun Zhang* \\ Laboratory of Environmental Biotechnology, Research Center for Eco-Environmental Sciences, Chinese Academy of Sciences, \\ P.O. Box 2871, Beijing 100085, China
}

Received 2 April 2002; received in revised form 9 October 2002; accepted 17 October 2002

\begin{abstract}
Cellulosic pyrolysate containing levoglucosan was chemically hydrolyzed and a maximum glucose yield of $17.35 \%$ was obtained by the hydrolysis with $0.2 \mathrm{~mol} / 1 \mathrm{H}_{2} \mathrm{SO}_{4}$ at $121^{\circ} \mathrm{C}$ for $20 \mathrm{~min}$. The total initial glucose was maintained at $41.9 \mathrm{~g} / 1$ by diluting the hydrolysate. Ten detoxification methods were employed including either single addition of solid $\mathrm{Ca}(\mathrm{OH})_{2}$ (to $\mathrm{pH} 6.0$ or 10.4) or its combinations with absorbents. The neutralization + diatomite shaking method gave the hydrolysate which was most completely fermented by Saccharomyces cerevisiae and Pichia sp. YZ-1. The maximal ethanol yield of $0.45 \mathrm{~g} / \mathrm{g}$ glucose was obtained by $S$. cerevisiae.

(C) 2002 Elsevier Science Ltd. All rights reserved.
\end{abstract}

Keywords: Pretreatment; Pyrolysate; Ethanol; Fermentation; Cellulose; Levoglucosan

\section{Introduction}

Cellulosic materials are abundant renewable resources in the world. The conversion of them into ethanol has been receiving increasing attention in recent years [1]. Over the past decades, emphasis has been placed on chemical and enzymatic hydrolysis of cellulosic materials to glucose that can be further fermented to ethanol by microorganisms. However, the overall conversion of cellulosic materials to glucose has been hampered by economic problems such as high costs of pretreatment and enzyme production

\footnotetext{
* Corresponding author. Tel.: +86-10-62849155; fax: +86-1062923563.

E-mail address: hxzhang@mail.rcees.ac.cn (H. Zhang).
}

[2]. Study advances in pyrolysis of cellulose may offer a new alternative for biomass pretreatment and saccharification, which can efficiently produce a high yield of viscous pyrolysate containing levoglucosan (an intramolecular glucoside between C-1 and C-6 of D-glucopyranose) in high concentration [3-10]. Unfortunately, it is difficult for microorganisms directly to convert the levoglucosan into ethanol $[9,11]$. Moreover, the cellulose-derived pyrolysate contains many other materials including aromatic species, aldehydes, furan and furfuryl derivatives, which are toxic to microorganisms [9]. Therefore, when cellulosic pyrolysate is considered as a fermentable substrate for producing ethanol, it will have to be pretreated by an economic way so that microorganisms can convert it into ethanol efficiently. 
The work reported here is on the investigation of hydrolysis and detoxification of cellulosic pyrolysate related to ethanol fermentation with the microorganisms of S. cerevisiae, P. sp. YZ-1 and Z. mobilis.

\section{Materials and methods}

\subsection{Preparation and pretreatment of pyrolysate}

Waste cotton cellulose used in the present investigation was from Beijing Spinning Mill in Beijing city. It contained $85-91 \%$ cellulose according to the data given by the mill. Its degree of polymerization (DP) and crystallinity were approximately 8100 and 55\% (by density method), respectively. The raw material was dried at $100^{\circ} \mathrm{C}$ to constant weight before it was pyrolyzed.

The pyrolysate was prepared by pyrolysis of the waste cotton cellulose with a slightly modified method by Zhuang et al. [12]. The pyrolysis was conducted in a 1.5-1 stainless-steel reactor under $1 \mathrm{~mm} \mathrm{Hg}$ vacuum at $400^{\circ} \mathrm{C}$ for $20 \mathrm{~min}$. About $80 \mathrm{~g}$ highly viscous pyrolysate per $100 \mathrm{~g}$ waste cotton was recovered from the pyrolysis reactor. Based on HPLC analysis, the primary material in the pyrolysate was levoglucosan, or its hydrolysis product, glucose. Their yields in the pyrolysate were approximately $43 \%(\mathrm{w} / \mathrm{w})$ and $5 \%$ $(\mathrm{w} / \mathrm{w})$, respectively. Water content in the pyrolysate was lower than $8 \%(\mathrm{w} / \mathrm{w})$.

The obtained pyrolysate was treated by two procedures. First, it was diluted with four-fold distilled water, then further supplemented with chemicals listed in Table 1 for hydrolysis by autoclaving at $121^{\circ} \mathrm{C}$ for $20 \mathrm{~min}$. Secondly, the pyrolysate hydrolyzed with $0.2 \mathrm{~mol} / 1 \mathrm{H}_{2} \mathrm{SO}_{4}$ was further diluted by distilled water to maintain the total initial glucose at $41.9 \mathrm{~g} / 1$. The dilution was then treated with a number of different ways as in Table 2 to reduce the effect of toxic components on ethanol production with microorganisms.

\subsection{Microorganisms and media}

Saccharomyces cerevisiae 2.399 and Zymomonas mobilis 10232 were obtained from China Center for Type Culture Collection, and Pichia sp. YZ-1 was isolated from the orchard soil in Beijing city and identified by our laboratory. Yeasts $S$. cerevisiae and
Table 1

Hydrolysis effects of different pretreatments on cellulosic pyrolysate

\begin{tabular}{|c|c|c|}
\hline Samples & $\begin{array}{l}\text { Glucose } \\
(\% \mathrm{w} / \mathrm{w})\end{array}$ & $\begin{array}{l}\text { Levoglucosan } \\
(\% \mathrm{w} / \mathrm{w})\end{array}$ \\
\hline Control $1^{\mathrm{a}}$ & $0.81 \pm 0.08$ & $10.43 \pm 1.12$ \\
\hline Control $2^{\mathrm{b}}$ & $2.32 \pm 0.15$ & $11.26 \pm 2.32$ \\
\hline $0.05 \mathrm{~mol} / 1 \mathrm{H}_{2} \mathrm{SO}_{4}$ & $13.12 \pm 1.16$ & $3.67 \pm 0.29$ \\
\hline $0.1 \mathrm{~mol} / 1 \mathrm{H}_{2} \mathrm{SO}_{4}$ & $15.69 \pm 1.41$ & $1.18 \pm 0.85$ \\
\hline $0.2 \mathrm{~mol} / 1 \mathrm{H}_{2} \mathrm{SO}_{4}$ & $17.35 \pm 1.48$ & $0.24 \pm 0.03$ \\
\hline $0.3 \mathrm{~mol} / 1 \mathrm{H}_{2} \mathrm{SO}_{4}$ & $16.95 \pm 1.02$ & $0.24 \pm 0.04$ \\
\hline $0.4 \mathrm{~mol} / 1 \mathrm{H}_{2} \mathrm{SO}_{4}$ & $16.75 \pm 1.16$ & ND \\
\hline $0.6 \mathrm{~mol} / 1 \mathrm{H}_{2} \mathrm{SO}_{4}$ & $16.14 \pm 1.32$ & ND \\
\hline $0.8 \mathrm{~mol} / 1 \mathrm{H}_{2} \mathrm{SO}_{4}$ & $16.04 \pm 1.19$ & ND \\
\hline $1.0 \mathrm{~mol} / 1 \mathrm{H}_{2} \mathrm{SO}_{4}$ & $15.14 \pm 1.77$ & ND \\
\hline $0.4 \mathrm{~mol} / 1 \mathrm{HCl}$ & $16.78 \pm 1.45$ & $0.49 \pm 0.03$ \\
\hline $0.3 \mathrm{~mol} / 1 \mathrm{H}_{3} \mathrm{PO}_{4}$ & $13.72 \pm 1.40$ & $8.10 \pm 0.90$ \\
\hline $0.4 \mathrm{~mol} / 1$ Peracetic acid & $4.65 \pm 0.44$ & $12.48 \pm 1.19$ \\
\hline $0.3 \mathrm{~mol} / 1 \mathrm{H}_{2} \mathrm{O}_{2}$ & $2.95 \pm 0.21$ & $9.90 \pm 1.02$ \\
\hline $\begin{array}{l}0.3 \mathrm{~mol} / 1 \mathrm{H}_{2} \mathrm{O}_{2} \\
\quad+0.03 \mathrm{~mol} / 1 \mathrm{FeCl}_{3}\end{array}$ & $3.34 \pm 0.31$ & $11.02 \pm 1.20$ \\
\hline $\begin{array}{l}0.3 \mathrm{~mol} / 1 \mathrm{H}_{2} \mathrm{O}_{2} \\
\quad+0.03 \mathrm{~mol} / 1 \mathrm{FeSO}_{4} \cdot \mathrm{H}_{2} \mathrm{O}\end{array}$ & $2.23 \pm 0.29$ & $12.01 \pm 1.67$ \\
\hline $\begin{array}{l}0.3 \mathrm{~mol} / 1 \mathrm{H}_{2} \mathrm{O}_{2} \\
\quad+0.03 \mathrm{~mol} / 1 \mathrm{MnSO}_{4}\end{array}$ & $1.98 \pm 0.18$ & $11.71 \pm 0.48$ \\
\hline $\begin{array}{l}0.3 \mathrm{~mol} / 1 \mathrm{H}_{2} \mathrm{O}_{2} \\
\quad+0.05 \mathrm{~mol} / 1 \mathrm{Al}_{2} \mathrm{O}_{3}\end{array}$ & $2.40 \pm 0.73$ & $11.42 \pm 1.67$ \\
\hline $\begin{array}{l}0.3 \mathrm{~mol} / 1 \mathrm{H}_{2} \mathrm{O}_{2} \\
\quad+0.3 \mathrm{~mol} / 1 \mathrm{NH}_{4} \mathrm{OH}\end{array}$ & $0.91 \pm 0.11$ & $16.37 \pm 1.54$ \\
\hline $2.5 \mathrm{~mol} / 1 \mathrm{NaOH}$ & $1.02 \pm 0.08$ & $16.21 \pm 1.01$ \\
\hline $0.3 \mathrm{~mol} / 1 \mathrm{NH}_{4} \mathrm{OH}$ & $0.66 \pm 0.07$ & $13.61 \pm 1.03$ \\
\hline
\end{tabular}

Note: values are means of triplicate \pm standard deviation. ND, no levoglucosan detected $(<0.02 \% \mathrm{w} / \mathrm{w})$.

${ }^{\mathrm{a}}$ Control without autoclaving.

${ }^{\mathrm{b}}$ Autoclaved control.

$P$. sp. YZ-1 were maintained on a medium containing $20.0 \mathrm{~g} / 1$ glucose, $20.0 \mathrm{~g} / 1$ peptone, $10.0 \mathrm{~g} / 1$ yeast extracts. Bacterium $Z$. mobilis was maintained in a liquid medium containing $20.0 \mathrm{~g} / 1$ glucose, $10.0 \mathrm{~g} / 1$ yeast extracts, $1.0 \mathrm{~g} / 1 \mathrm{MgCl}_{2}, 1.0 \mathrm{~g} / 1\left(\mathrm{NH}_{4}\right)_{2} \mathrm{SO}_{4}$, $1.0 \mathrm{~g} / 1 \mathrm{KH}_{2} \mathrm{PO}_{4}$, $\mathrm{pH} 5.5$.

The growth medium used for preparing yeast inocula consisted of $10.0 \mathrm{~g} / 1$ yeast extracts, $6.4 \mathrm{~g} / 1$ urea, $2.0 \mathrm{~g} / 1 \mathrm{KH}_{2} \mathrm{PO}_{4}, 1.0 \mathrm{~g} / 1 \mathrm{MgSO}_{4} \cdot 7 \mathrm{H}_{2} \mathrm{O}$, and the hydrolysate that was treated with neutralization method and then diluted by distilled water to a final concentration of $20.0 \mathrm{~g} / 1$ glucose, at $\mathrm{pH} 5.5$. The fermentation medium used for ethanol production from hydrolysate with yeast was identical to its growth medium except that the glucose concentration varied with different pretreatment experiments as shown in Table 2. 
Table 2

Fermentation parameters obtained at fermentations of the cellulosic pyrolysate-derived hydralysates by $S$. cerevisiae $(S$. c ) and $P$. sp. YZ-1 ( $P$. sp.) with an initial total glucose concentration of $41.9 \mathrm{~g} / 1$ before any pretreatments

\begin{tabular}{|c|c|c|c|c|c|c|c|}
\hline \multirow[t]{2}{*}{ Pretreatment } & \multirow{2}{*}{$\begin{array}{l}\text { Glucose } \\
\text { after } \\
\text { pretreatment } \\
\mathrm{S}(\mathrm{g} / \mathrm{l})\end{array}$} & \multicolumn{2}{|c|}{$\begin{array}{l}\text { Time for } \\
\text { maximal } \\
\text { ethanol }(\mathrm{h})\end{array}$} & \multicolumn{2}{|c|}{$\begin{array}{l}\text { Maximal ethanol } \\
p(\mathrm{~g} / \mathrm{l})\end{array}$} & \multicolumn{2}{|c|}{$\begin{array}{l}Y_{\mathrm{p} / \mathrm{s}}(\mathrm{g} \text { ethanol } / \mathrm{g} \\
\text { glucose }) \\
(\mathrm{g} / \mathrm{g})\end{array}$} \\
\hline & & S. $c$ & P. sp. & S. $c$. & P. sp. & S. $c$. & $P$. sp. \\
\hline Neutralization $^{\mathrm{a}}$ & $33.6 \pm 1.07$ & 24 & 110 & $15.1 \pm 1.07$ & $12.3 \pm 1.05$ & 0.45 & 0.37 \\
\hline Neutralization + activated carbon shaking ${ }^{b}$ & $34.4 \pm 0.89$ & 24 & 110 & $15.4 \pm 1.10$ & $13.6 \pm 0.81$ & 0.45 & 0.40 \\
\hline Neutralization+diatomite shaking ${ }^{\mathrm{b}}$ & $35.9 \pm 1.32$ & 24 & 110 & $16.1 \pm 1.31$ & $15.1 \pm 1.33$ & 0.45 & 0.42 \\
\hline Neutralization+bentomite shaking ${ }^{b}$ & $35.7 \pm 1.21$ & 24 & 110 & $14.8 \pm 1.21$ & $14.7 \pm 0.91$ & 0.42 & 0.41 \\
\hline Neutralization+zeolite shaking ${ }^{\mathrm{b}}$ & $33.6 \pm 1.73$ & 24 & 110 & $14.8 \pm 1.67$ & $13.6 \pm 1.22$ & 0.44 & 0.41 \\
\hline Over-liming ${ }^{\mathrm{c}}$ & $33.7 \pm 0.92$ & 24 & 110 & $13.2 \pm 1.83$ & $12.3 \pm 1.91$ & 0.39 & 0.37 \\
\hline Over-liming+activated carbon shaking ${ }^{\mathrm{d}}$ & $35.2 \pm 1.10$ & 24 & 110 & $12.3 \pm 1.79$ & $12.7 \pm 1.25$ & 0.35 & 0.36 \\
\hline Over-liming + diatomite shaking ${ }^{\mathrm{d}}$ & $35.0 \pm 1.73$ & 24 & 110 & $15.3 \pm 0.81$ & $13.2 \pm 1.54$ & 0.44 & 0.38 \\
\hline Over-liming + bentonite shaking ${ }^{\mathrm{d}}$ & $31.6 \pm 1.74$ & 24 & 110 & $13.2 \pm 2.03$ & $11.8 \pm 2.49$ & 0.42 & 0.37 \\
\hline Over-liming +zeolite shaking ${ }^{\mathrm{d}}$ & $33.3 \pm 1.51$ & 24 & 110 & $13.6 \pm 1.21$ & $11.8 \pm 1.25$ & 0.41 & 0.35 \\
\hline
\end{tabular}

Note: values are means of triplicate \pm standard deviation.

${ }^{\mathrm{a}} \mathrm{pH}$ was adjusted to 6.0 by adding solid $\mathrm{Ca}(\mathrm{OH})_{2}$, and then precipitate was removed by filtration through $0.45 \mu \mathrm{m}$ membrane.

${ }^{\mathrm{b}}$ After neutralization, the hydrolysate was treated respectively with four adsorbents: activated carbon, diatomite, bentonite, zeolite $(10 \%$ $\mathrm{w} / \mathrm{v}$ ) by stirring for $80 \mathrm{~min}$, and then the precipitate was removed by filtration repeatedly.

${ }^{\mathrm{c}} \mathrm{pH}$ was first adjusted to 10.4 by adding solid $\mathrm{Ca}(\mathrm{OH})_{2}$, and then readjusted to 6.0 by $\mathrm{H}_{2} \mathrm{SO}_{4}$, and finally the precipitate was removed by filtration through $0.45 \mu \mathrm{m}$ membrane after each adjustment.

${ }^{\mathrm{d}}$ After over-liming, the hydrolysate was treated respectively with four adsorbents: activated carbon, diatomite, bentonite, zeolite (10\% $\mathrm{w} / \mathrm{v}$ ) by stirring for $80 \mathrm{~min}$, and then the precipitate was removed by filtration repeatedly.

Table 3

Fermentation parameters obtained from cellulosic pyrolysate-derived hydralysates by Z. mobilis for $168 \mathrm{~h}$ with an initial total glucose concentration of $41.9 \mathrm{~g} / 1$ before any pretreatments

\begin{tabular}{lllll}
\hline Pretreatment & $\begin{array}{l}\text { Glucose after } \\
\text { Pretreatment } \\
S(\mathrm{~g} / \mathrm{l})\end{array}$ & $\begin{array}{l}\text { Residual } \\
\text { glucose } \\
S_{\mathrm{o}}(\mathrm{g} / \mathrm{l})\end{array}$ & $\begin{array}{l}\text { Ethanol } \\
p(\mathrm{~g} / \mathrm{l})\end{array}$ & $\begin{array}{l}Y_{\mathrm{P} /\left(S-S_{\mathrm{o}}\right)}(\mathrm{g} \text { ethanol/g } \\
\text { glucose }) \\
(\mathrm{g} / \mathrm{g})\end{array}$ \\
\hline Neutralization $^{\mathrm{a}}$ & $33.6 \pm 1.07$ & $30.2 \pm 1.15$ & $1.5 \pm 0.14$ & 0.44 \\
Neutralization+activated carbon shaking $^{\mathrm{b}}$ & $34.4 \pm 0.89$ & $30.5 \pm 1.73$ & $1.7 \pm 0.11$ & 0.44 \\
Neutralization+diatomite shaking $^{\mathrm{b}}$ & $35.9 \pm 1.32$ & $31.8 \pm 2.01$ & $1.8 \pm 0.12$ & 0.44 \\
Neutralization+bentomite shaking $^{\mathrm{b}}$ & $35.7 \pm 1.21$ & $31.6 \pm 1.12$ & $1.7 \pm 0.12$ & 0.41 \\
Neutralization+zeolite shaking $^{\mathrm{b}}$ & $33.6 \pm 1.73$ & $29.8 \pm 1.40$ & $1.6 \pm 0.11$ & 0.42 \\
Over-liming $^{\mathrm{c}}$ & $33.7 \pm 0.92$ & $30.4 \pm 1.55$ & $1.4 \pm 0.11$ & 0.42 \\
Over-liming+activated carbon shaking $^{\mathrm{d}}$ & $35.2 \pm 1.10$ & $31.8 \pm 1.30$ & $1.5 \pm 0.06$ & 0.44 \\
Over-liming+diatomite shaking $^{\mathrm{d}}$ & $35.0 \pm 1.73$ & $31.4 \pm 1.55$ & $1.5 \pm 0.14$ & 0.42 \\
Over-liming+bentomite shaking $^{\mathrm{d}}$ & $31.6 \pm 1.74$ & $28.3 \pm 1.45$ & $1.3 \pm 0.10$ & 0.39 \\
Over-liming+zeolite shaking $^{\mathrm{d}}$ & $33.3 \pm 1.51$ & $29.7 \pm 1.61$ & $1.5 \pm 0.08$ & 0.42 \\
\hline
\end{tabular}

Note: values are means of triplicate \pm standard deviation.

Footnotes a,b,c,d are as shown in Table 2.

For Z. mobilis, the growth medium used for preparing inocula consisted of $10.0 \mathrm{~g} / 1$ yeast extracts, $1.0 \mathrm{~g} / 1$ $\mathrm{MgCl}_{2}, 1.0 \mathrm{~g} / 1\left(\mathrm{NH}_{4}\right)_{2} \mathrm{SO}_{4}, 1.0 \mathrm{~g} / 1 \mathrm{KH}_{2} \mathrm{PO}_{4}$, and the hydrolysate which was identical to that in the growth medium of yeast, at $\mathrm{pH} 5.5$. The fermentation medium of $Z$. mobilis was identical to its growth medium except that the glucose concentration varied with different pretreatment experiments as shown in Table 3. 
When preparing these media, mineral salts, urea and yeast extracts were autoclaved separately at $121^{\circ} \mathrm{C}$ for $30 \mathrm{~min}$, and then added to the different treated hydrolysates, aseptically.

\subsection{Inoculum preparation and fermentation}

Yeast inocula were prepared by using slant cultures to inoculate $20 \mathrm{ml}$ of sterile growth medium (see above) contained in 50-ml cotton plug-stoppered Erlenmeyer flasks. The flasks were incubated with shaking $(150 \mathrm{rpm})$ at $30^{\circ} \mathrm{C}$ for $48 \mathrm{~h}$. Based on HPLC analysis, the glucose from the hydrolysate in the medium was not detected till $48 \mathrm{~h}$.

Z. mobilis inoculum was prepared by the same way as the yeast inoculum except that incubation was for $110 \mathrm{~h}$. Z. mobilis was extremely sensitive to the medium containing the hydrolysate and grew very slowly in it. It used up glucose till $110 \mathrm{~h}$.

A $10 \%(\mathrm{v} / \mathrm{v})$ inoculum was used for subsequent subcultures. Ethanol fermentations with $S$. cerevisiae, $P$. sp. YZ-1 and Z. mobilis were evaluated at $30^{\circ} \mathrm{C}$ in 150-ml Erlenmeyer flasks having $100 \mathrm{ml}$ appropriate media at $150 \mathrm{rpm}$. The flasks were sealed with a one-hole rubber stopper, in which a glass tube was connected to an air lock filled with sulfuric acid solution $(40 \%$ concentrated sulfuric acid).

\subsection{Analytical methods}

The analyses of glucose, levoglucosan in pyrolysate and its hydrolysate were performed on an HPLC system (GRE-3A, Shimadzu Corporation, Kyoto, Japan) equipped with a Waters Model 401 refractive index detector and a Transgenomic ICSep ICE-ORH-801 column $(300 \times 6.5 \mathrm{~mm})($ Transgenomic Inc., San Jose, CA, USA). The mobile phase was $0.0025 \mathrm{~N}$ sulfuric acid at $0.6 \mathrm{ml} / \mathrm{min}$, the injection volume was $10 \mu \mathrm{l}$ and the column temperature was maintained at $30^{\circ} \mathrm{C}$. Three replicate samples were evaluated by HPLC.

Glucose and ethanol in fermentation liquid were also analyzed by HPLC. Samples $(5 \mathrm{ml})$ were collected from the given flasks, respectively, and centrifuged at $4{ }^{\circ} \mathrm{C}$ for $20 \mathrm{~min}$ at $5000 \times g$ to remove cells, and the supernatant fluid was used for the determination of ethanol and glucose concentration. Mean values \pm standard deviation for three flasks per experiment are presented.
All reagents used in this work were of analytical grade.

\section{Results and discussion}

\subsection{Hydrolysis of pyrolysate}

The cellulose-derived pyrolysate was hydrolyzed by employing the sterilization conditions $\left(121^{\circ} \mathrm{C}\right.$, $20 \mathrm{~min}$ ), which could avoid the subsequent sterilization procedure in using the treated pyrolysate as fermentable substrates. The pyrolysate was acidic at about $\mathrm{pH} 2$. However, under the sterilization conditions, the little acidity was not enough to hydrolyze levoglucosan in the pyrolysate to glucose completely as the result of control 2 in Table 1 , so more acidic catalyst was needed. Table 1 shows that additional sulfuric acid was more effective in hydrolysis of the pyrolysate than the other chemicals. Furthermore, $0.2 \mathrm{~mol} / 1 \mathrm{H}_{2} \mathrm{SO}_{4}$ gave a maximal glucose yield of $17.35 \%$. A further increase (higher than $0.2 \mathrm{~mol} / \mathrm{l}$ ) in acid concentration led to a decrease of the glucose yield (lower than $17.35 \%$ ), which could be due to glucose decomposition during the hydrolysis of the pyrolysate. Although hydrogen peroxide is environmentally friendly, our experimental results using it as treatment agent of the pyrolysate were not ideal. Under the alkaline conditions, levoglucosan was stable and more levoglucosan was produced in the pyrolysate (Table 1 ).

It should be pointed that, compared with the controls, over-stoichiometrical conversion of levoglucosan to glucose was interesting under the optimal acid hydrolysis $\left(0.2 \mathrm{~mol} / 1 \mathrm{H}_{2} \mathrm{SO}_{4}, 121^{\circ} \mathrm{C}\right.$ and $20 \mathrm{~min}$ ), which suggested that glucose came not only from levoglucosan, but also possibly from small amounts of unknown carbohydrate oligomers in the pyrolysate. The observation was further confirmed by the subsequent experimental results that amounts of levoglucosan also increased under the alkaline hydrolysis. According to the report by Bonn [6], besides main levoglucosan and glucose, cellobiose and other three unknown gluco-oligomers were also founded in the pyrolysate from wood or cotton by the analyses of three different HPLC systems. In this experiment, probably similar oligomers (cellobiose or other sugars) in the cellulosic pyrolysate were decomposed 
into glucose or levoglucosan with the hydrolysis of the pyrolysate by acid or alkaline, which would increase total amounts of glucose or levoglucosan in the acid or alkaline hydrolysate.

\subsection{Detoxification and fermentation}

The toxic materials could be either removed or transformed into inactive compounds by various physico-chemical treatments such as extraction, neutralization, over-liming, evaporation and steaming stripping, adsorbent adsorption and ion exchange resins [13-15]. In the cellulosic pyrolysate, some toxic materials (aromatic species, furan, furfuryl derivatives, etc.) that inhibited microorganisms could be transformed into inactive compounds with levoglucosan converted to glucose when the pyrolysate was hydrolyzed with sulfuric acid. This phenomenon had been observed by Prosen et al. [9]. However, in our preliminary experiments, two yeast strains (S. cerevisiae and $P$. sp.YZ-1) and the bacterium strain (Z. mobilis) grew slowly and poorly on solid medium containing acid-hydrolyzed pyrolysate compared with that on pure glucose medium. Therefore, it was necessary for the hydrolysate used for ethanol fermentation to do further detoxification pretreatment.

To achieve efficient detoxification methods for ethanol production from the hydrolysate, $\mathrm{Ca}(\mathrm{OH})_{2}$ and absorbents (activated carbon, diatomite, bentonite, zeolite) were used for doing different detoxification experiments. Table 2 summarizes the treatment procedures of detoxification and the experimental results of ethanol fermentations with $S$. cerevisiae and P. sp.YZ-1.

Before any detoxification treatments, the glucose concentration in the hydrolysate was $41.9 \mathrm{~g} / 1$. After treatments respectively by different detoxification methods, glucose concentrations decreased by $6.0-10.3 \mathrm{~g} / 1$. The maximum concentration of glucose $(35.9 \mathrm{~g} / \mathrm{l})$ occurred in the hydrolysate treated by the method of neutralization and diatomite adsorption.

To compare the effect of detoxification on ethanol production, S. cerevisiae, $P$. sp.YZ-1 and Z. mobilis were selected because they were reasonably efficient converters of glucose and also sufficiently robust to be well suited to industrial operations. The test results showed that the single neutralization method and its sequential uses with the four different adsorbents gave a substantial improvement in ethanol production, compared with the single over-liming method and its combinations with the four different adsorbents. The total average values of ethanol yields obtained by $S$. cerevisiae and $P$. sp. YZ-1 from the treatments of the single neutralization method and its sequential uses with the four different adsorbents were 0.44 and $0.40 \mathrm{~g} / \mathrm{g}$, respectively, whereas that from the treatments of the single over-liming method and its combinations with the four different adsorbents were only 0.40 and $0.37 \mathrm{~g} / \mathrm{g}$, respectively. Moreover, the adsorbent diatomite was obviously better in improving the fermentability of the hydrolysate than the other adsorbents (activated carbon, bentonite, zeolite). Under similar conditions (after the hydrolysate treated by neutralization or over-liming), the ethanol yields obtained by $S$. cerevisiae from the treatment of diatomite absorption were 0.45 and $0.44 \mathrm{~g} / \mathrm{g}$, respectively, and that obtained by $P$. sp. YZ-1 were 0.42 and $0.38 \mathrm{~g} / \mathrm{g}$, respectively. They were higher or at least no lower than that of other three absorption treatments.

From the data in Table 2, the ability of all applied methods to enhance the bioconversion rate was higher for $S$. cerevisiae than that for $P$. sp. YZ-1. A maximal ethanol concentration of $16.1 \mathrm{~g} / 1$ was obtained from the hydrolysate containing $35.9 \mathrm{~g} / 1 \mathrm{glu}-$ cose in $24 \mathrm{~h}\left(Y_{\mathrm{p} / \mathrm{s}}=0.45 \mathrm{~g} / \mathrm{g}\right)$ with $S$. cerevisiae. The best ethanol concentration with $P$. sp. YZ-1 from the similarly treated hydrolysate was $15.1 \mathrm{~g} / 1$ in $110 \mathrm{~h}$ $\left(Y_{\mathrm{p} / \mathrm{s}}=0.42 \mathrm{~g} / \mathrm{g}\right)$.

Z. mobilis was demonstrated not to be suitable for fermenting all treated hydrolysates to ethanol in this work (see Table 3). Even for the ethanol fermentation of the hydrolysate treated with the neutralization + diatomite shaking method, ethanol concentration was only $1.8 \mathrm{~g} / 1$ and only $4.1 \mathrm{~g} / 1 \mathrm{glu}-$ cose was utilized after 7-day fermentation. This result, however, was the best in all fermentations, which further confirmed that the neutralization + diatomite shaking method was the best in tested detoxification treatments (as shown in Table 3). For the fermentations of the other treated hydrolysates to ethanol, the ethanol concentrations were lower than that from the neutralization + diatomite shaking method. This suggested that $Z$. mobilis was more sensitive to the toxic substances not removed by the various pretreatments than the yeasts used in this work. Prosen et al. [9] observed similar results that Sporobolomyces 
salmonicolor ATCC 16406 and Cryptococcus albidus ATCC 20293 of the seven yeasts could not grow on the substrate of the wood pyrolysate-derived hydrolysate at all, whereas the other five yeasts could grow well.

In conclusion, it was clear that the cellulose pyrolysate that was hydrolyzed by mild acid $(0.2 \mathrm{~mol} / 1$ $\mathrm{H}_{2} \mathrm{SO}_{4}$ ) and followed by the treatments of the neutralization and diatomite adsorption was suitable for ethanol fermentation with $S$. cerevisiae 2.399. This provided a new alternative for fuel ethanol production using waste cotton, which was also helpful for fermenting the pyrolysate from other cellulosic materials to ethanol. It should be emphasized that this work focused on the comparison of effects of different pretreatment methods for the cellulosic pyrolysate on ethanol production, and $S$. cerevisiae, $P$. sp. YZ-1 and $Z$. mobilis were used to identify which detoxification treatment for acid-hydrolyzed pyrolysate was the most efficient on ethanol fermentation. With regard to optimization of fermentation conditions (controlled fermentation, addition of different nutrients and strain preadaptation) and the investigation of fermentation time course, these experiments will be designed and carried out in a 5-1 fermentor with S. cerevisiae 2.399 and will be reported in the next paper.

\section{Acknowledgements}

This work was supported by grants from the Chinese Academy of Sciences. The authors wish to express their thanks to Dr. H.Y. Qi for her advice and Dr. X.L. Zhuang, Mr. Z.H. Bai, Mr. L. Li and Mr. W.T. Lin for their technical assistance.

\section{References}

[1] Chandrakant P, Bisaria VS. Simultaneous bioconversion of cellulose and hemicellulose to ethanol. Critical Reviews in Biotechnology 1998;18:295-331.
[2] Kumakura M. Preparation of immobilized cellulase beads and their application to hydrolysis of cellulosic materials. Process Biochemistry 1997;32:555-9.

[3] Golova OP. Chemical effects of heat on cellulose. Russian Chemical Reviews 1975;44:687.

[4] Shafizadeh F, Furneaux RH, Cochran TG, Scholl JP, Sakai Y. Production of levoglucosan and glucose from pyrolysis of cellulosic materials. Journal of Applied Polymer Science 1979;23:3525-39.

[5] Shafizadeh F, Stevenson TT. Saccharification of douglas-fir wood by a combination of prehydrolysis and pyrolysis. Journal of Applied Polymer Science 1982;27:4577-85.

[6] Bonn G. Analytical determination of 1, 6-anhydro- $\beta$ D-glucopyranose and kinetic studies under hydrothermal conditions. Journal of Carbohydrate Chemistry 1985;4: 405-19.

[7] Piskorz J, Radlein D, Scott DS, Czernik S. Pretreatment of wood and cellulose for production of sugars by fast pyrolysis. Journal of Analytical and Applied Pyrolysis 1989;16:127-36.

[8] Radlein D, Piskorz J, Scott DS. Fast pyrolysis of natural polysaccharides as a potential industrial process. Journal of Analytical and Applied Pyrolysis 1991;19:41-63.

[9] Prosen EM, Radlein D, Piskorz J, Scott DS, Legge RL. Microbial utilization of levoglucosan in wood pyrolysate as a carbon and energy source. Biotechnology and Bioengineering 1993;42:538-41.

[10] Brown RC, Radlein D, Piskorz J. Pretreatment processes to increase pyrolytic yield of levoglucosan from herbaceous feedstocks. In: Bosell JJ, editor. American chemical society symposium, series no.784. Washington, DC, USA: American Chemical Society, 2001. p. 123-34.

[11] Nakagawa M, Sakai Y, Yasui T. Itaconic acid fermentation of levoglucosan. Journal of Fermentation Technology 1984;62:201-3.

[12] Zhuang XL, Zhang HX, Yang JZ, Qi HY. Preparation of levoglucosan by pyrolysis of cellulose and its citric acid fermentation. Bioresource Technology 2001;79:63-6.

[13] van Zyl C, Prior BA, du Preez JC. Production of ethanol from sugarcane bagasse hemicellulose hydrolysate by Pichia stipitis. Applied Biochemistry and Biotechnology 1988;17:357-69.

[14] Eken-Saraçoğlu N, Arslan Y. Comparison of different pretreatments in ethanol fermentation using corn cob hemicellulosic hydrolysate with Pichia stipitis and Candida shehatae. Biotechnology Letter 2000;22:855-8.

[15] Silva CJSM, Roberto IC. Improvement of xylitol production by Candida guilliermondii FTI 20037 previously adapted to rice straw hemicellulosic hydrolysate. Letters in Applied Microbiology 2001;32:248-52. 